\title{
Optimization of an analytical HPLC-DAD method for detecting hydroxycinnamic acid derivatives from mixtures of Saussurea grandifolia and Taraxacum coreanum
}

\author{
Hak-Dong Lee 1 , Leo Adrianne Paje' ${ }^{1}$ Sullim Lee², Ki Sung Kang ${ }^{3}$, Kyungki Hong ${ }^{4}$, Hyukjin Kwon ${ }^{4}$ and
} Sanghyun Lee L, $^{*}$

\begin{abstract}
An analytical method was established to identify and quantify hydroxycinnamic acids, such as 1,5-dicaffeoylquinic acid (DCQA) and chicoric acid (CA), in mixtures of Saussurea grandifolia and Taraxacum coreanum (MST) by using reverse-phase high-performance liquid chromatography coupled with diode array detector (HPLC-DAD). Analyses were carried out by using an INNO $C_{18}$ column with a gradient elution system, and different parameters were used to validate our optimized method. Results demonstrated limits of detection and quantification of $5.46 \times 10^{-3}$ and $16.54 \times 10^{-3} \mathrm{mg} / \mathrm{mL}$ for DCQA and $0.37 \times 10^{-3}$ and $1.14 \times 10^{-3} \mathrm{mg} / \mathrm{mL}$ for CA, respectively. The calibration curves for DCQA and CA showed good linearity over the concentration ranges of $0.025-0.4$ and $0.00625-0.1 \mathrm{mg} / \mathrm{mL}$, respectively, and both exhibited $r^{2}=1.0000$. In the accuracy test, high recovery rates were obtained ranging from 101.16-104.18\% for DCQA and $97.55-108.49 \%$ for CA, while the precision values were $\leq 1.00 \%$ for DCQA and $\leq 1.21 \%$ for CA. The values obtained from our analyses support the use of this analytical method for the accurate identification and quantification of DCQA and CA from MST. Our methodology could be used further to determine the content of hydroxycinnamic acid derivatives in routine analyses and large-scale extraction processes.
\end{abstract}

Keywords: Chicoric acid, 1,5-Dicaffeoylquinic acid, HPLC-DAD, Method validation, Saussurea grandifolia, Taraxacum coreanum

\section{Introduction}

Dandelions are plants of the genus Taraxacum and are perennial herbs of the Compositae family that are widely distributed across the warm northern hemisphere, including Asia, Europe, and America. There are about 2000 species of dandelions in the world, which are often highly recognizable because they grow well-trafficked areas like by roads and in open grass fields. Plants in the genus Taraxacum have historically been used as

\footnotetext{
*Correspondence: slee@cau.ac.kr

${ }^{1}$ Department of Plant Science and Technology, Chung-Ang University,

Anseong 17546, Republic of Korea

Full list of author information is available at the end of the article
}

medicinal herbs because of their various bioactivities. For example, they have been used to treat inflammation and rheumatism [1]. Its medicinal effects include serving as an anti-oxidant and anti-cancer agent, as well as being hepatoprotective, neuroprotective, and useful in treating atopy [2-8]. Among plants in the genus Taraxacum, T. coreanum is known as "white dandelion" and is native to Korea. Diverse phytochemical compounds in T. coreanum, such as sterols, terpenoids, and phenolics among others, have been reported [8-10].

Plants in the genus Saussurea of the Compositae family have been broadly consumed as "edible wild plants" in Korea. The genus Saussurea is widely distributed throughout the northern hemisphere, but mainly in Asia. 
They are also well-diversified in Korea where 32 species have been identified [11], 16 species of which have been reported as endemic [12]. In China, some species have been used as traditional medicines to treat rheumatism, bleeding, and gynecological diseases [13]. They contain various phytochemicals that include flavonoids, sesquiterpenoids, triterpenes, lignans, and steroids $[14,15]$. This imparts the plants in the genus Saussurea with healthpromoting properties. Such plants can exhibit antiinflammatory, anti-bacterial, and anti-fungal activities [16-19], as well as the capacity to regulate plant growth $[20,21]$.

Recently, the consumption of health functional foods has steadily increased due to individual's efforts and interest in self-health care, especially enhancing immunity due to aging and epidemic trends. Health functional foods can have a direct impact on promoting health and preventing disease by increasing the intake of food ingredients that benefit overall health [22]. As a result of this trend, developing health functional foods from medicinal plants and natural product materials has emerged as a high value-added industry, drawing attention as an industrial area with the highly attractive market outlook among the various biological industries. Different plants are often combined into a mixture that integrates various functions according to consumer needs. This trend requires a certified method or a precise analysis method to evaluate functional and marker compounds to standardized distributions in health functional foods.

Plenty of hydroxycinnamic acid derivatives are found in the two genera mentioned above. There have been many studies where hydroxycinnamic acid derivatives were already determined and quantified [23-25], but studies on its method validation are insufficient. Therefore, it is meaningful and necessary to establish a validated analytical method for 1,5-dicaffeoylquinic acid (DCQA) and chicoric acid (CA) from mixtures of S. grandifolia and T. coreanum (MST). In order to utilize a plant derived material as a functional ingredient, at least one marker compound needs to be standardized, developed, and verified. Analytical method validation is a set of procedures for establishing whether an analytical method is reproducible and provides reliable results when used for the intended purpose [26]. These validation procedures have gained wide acceptance as a criterion for determining the validity of analytical methods used for the quality control of health-related functional foods and pharmaceuticals [27].

In this study, we established a practical and appropriate analytical method that uses HPLC-DAD to quantify marker compounds in MST. This proposed method is validated by analyzing hydroxycinnamic acids, such as DCQA and CA, in MST by using HPLC-DAD, which is useful as a basis for developing a high value-added health product derived from MST.

\section{Materials and methods}

\section{Plant materials and extraction procedure}

The plants S. grandifolia and T. coreanum were collected from Ulneung Island (Kyungpook Province, Korea) and Haman (Kyungnam Province, Korea), respectively. MST was composed of mixtures of S. grandifolia and T. core$\operatorname{anum}(1: 4, w / w)$ extracts. Voucher specimen of $S$. grandifolia (No. LEE 2011-02) and T. coreanum (No. LEE 2007-01) were identified by Dr. K. Choi, Korea National Herbarium, Korea. Dried aerial parts of the plants were pulverized and used for extraction. Each plant (100 g) was extracted three times with ethanol $\left(80^{\circ} \mathrm{C}, 2 \mathrm{~L} \times 3 \mathrm{~h}\right)$ and concentrated in vacuo $\left(50^{\circ} \mathrm{C}\right)$.

\section{Instrumentation, chemicals, and reagents}

Analyses were performed by using an HPLC system (Agilent 1260 Infinity II Quat Pump, CA, USA) that consisted of an auto-sampler, pump, and photodiode array detector (PDA WR detector, CA, USA). HPLC-grade solvents such as water, methanol $(\mathrm{MeOH})$, and acetonitrile (ACN) were purchased from J. T. Baker (Phillipsburg, PA, USA). Acetic acid (99.7\%) and ethanol (95.0\%) were purchased from Samchun Pure Chemicals (Pyeongtaek, Korea). DCQA (98.9\%) and CA (97.5\%) were commercially acquired from Natural Product Institute of Science and Technology (www.nist.re.kr), Anseong, Korea (Fig. 1).

\section{Preparation of samples and standard solutions for HPLC}

MST (70 mg) was dissolved in $1 \mathrm{~mL} \mathrm{MeOH}$ and filtered through a syringe filter $(0.45-\mu \mathrm{m})$ to prepare sample stock solutions. One milligram each of DCQA and CA was dissolved in $1 \mathrm{~mL} \mathrm{MeOH}$ to prepare the standard stock solutions. Calibration curves were obtained by diluting stock solutions to the desired concentrations to prepare the working solutions and subsequently analyzing these working solutions.

\section{HPLC-DAD conditions}

HPLC analysis was conducted with a reverse-phase HPLC system equipped with an INNO $\mathrm{C}_{18}$ column $(25 \mathrm{~cm} \times 4.6 \mathrm{~mm}, 5 \mu \mathrm{m})$. The injection volume was 10 $\mu \mathrm{L}$ and a wavelength of $330 \mathrm{~nm}$ was used for detection. Analyses were conducted at ambient temperature with a flow rate of $1.0 \mathrm{~mL} / \mathrm{min}$. A gradient elution system was used for analysis. The mobile phase was $0.5 \%$ acetic acid in water (A) and $\mathrm{ACN}(\mathrm{B})$. The elution was conducted as follows: $90 \% \mathrm{~A}$ at $0 \mathrm{~min}$, followed by $80 \% \mathrm{~A}$ from 0 to $18 \mathrm{~min}$, then $73 \% \mathrm{~A}$ from 18 to $30 \mathrm{~min}, 0 \% \mathrm{~A}$ from 30 to $35 \mathrm{~min}$ which, $0 \%$ A was maintained until $47 \mathrm{~min}, 90 \%$ A 


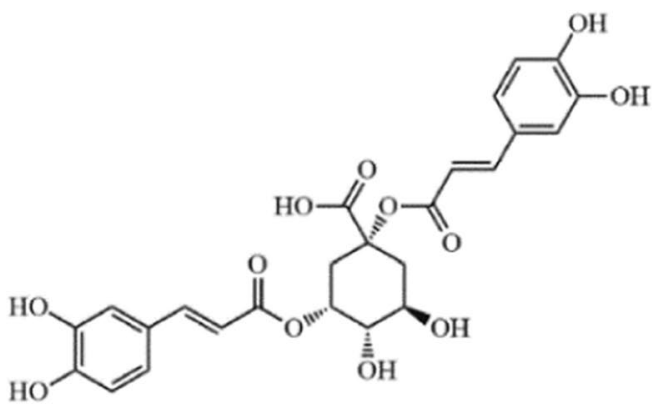

DCQA<smiles>O=C(/C=C/c1ccc(O)c(O)c1)O[C@H](C(=O)O)[C@H](OC(=O)/C=C/c1ccc(O)c(O)c1)C(=O)O</smiles>

CA

Fig. 1 Chemical structures of 1,5-dicaffeoylquinic acid (DCQA) and chicoric acid (CA)

from 47 to 50 min, and $90 \%$ A was then maintained until $60 \mathrm{~min}$.

\section{Method validation}

The specificity, accuracy, precision, limit of detection (LOD), limit of quantification (LOQ), and linearity of the new HPLC method were validated. The HPLC method was validated following the guidelines provided by the International Council for Harmonisation of Technical Requirements for Pharmaceuticals for Human Use [28]. The specificity of the method was tested to see whether there was any interference between the retention times and UV spectra of the standards and MST, and if the peaks indicated the presence of the same compounds. HPLC method accuracy was measured by conducting recovery tests in which sample extracts were spiked with four different standard mixtures at various concentrations and calculating the recovery (\%) of the two compounds in the extract. To validate precision, three different concentrations of sample extracts were used for intra-day (repeatability) analysis, and only one concentration for the inter-day (intermediate precision) analysis in triplicate. Intra and inter-day precision were examined by calculating the percent of relative standard deviation (\% RSD) of the standards on the same day and on three different days, respectively. Linearity was assessed by using five concentration levels of each standard solution (0.025-0.4 for DCQA and $0.00625-0.1 \mathrm{mg} / \mathrm{mL}$ for CA) with three injections. Using the peak areas measured at $330 \mathrm{~nm}$ on the chromatogram, a calibration curve was plotted against the known concentrations of the standard solutions. Linear least-squares regression was used to analyze the standard curves of DCQA and CA, and the correlation coefficient $\left(r^{2}\right)$ of the regression formula were used to validate the linearity. The calibration curve of each standard compound was obtained by fitting, and the standard deviation values of the intercept $(\sigma)$ and the slope $(\mathrm{S})$ were used to calculate the LOD and LOQ. The LOD is the lowest amount or concentration of analyte that can be reliably distinguished from the base line and the LOQ is the lowest amount of analyte that can be quantified with acceptable repeatability and accuracy. The standard deviation of the response and the slope of calibration were used to obtain the LOD and LOQ values. The LOD and LOQ were derived using the following formulas: $\mathrm{LOD}=3.3(\sigma / \mathrm{S})$ and $\mathrm{LOQ}=10(\sigma / \mathrm{S})$.

\section{Calibration curves}

Concentrations of the standard solutions were plotted with their respective peak areas to prepare the calibration curves. The correlation coefficient $\left(r^{2}\right)$ of the calibration curve was used to determine the linearity of the fitted line, and the DCQA and CA concentrations in the samples were then calculated from the calibration curve. The calibration functions were determined based on the peak area $(Y)$, concentration $(X, \mathrm{mg} / \mathrm{mL})$, and mean \pm standard deviation $(\mathrm{n}=3)$.

\section{Results and discussion}

An analytical HPLC method that quantifies DCQA and CA in MST was developed and validated. The two different compounds were analyzed by using HPLC-DAD, the results of which are shown in Fig. 2. The retention time was $16.0 \mathrm{~min}$ for DCQA and $19.6 \mathrm{~min}$ for CA, showing excellent separation. A wavelength of $330 \mathrm{~nm}$ provided the most effective response for quantifying DCQA and CA, including all impurities, in a single run. No impurity peaks were detected in quantifying DCQA and CA, suggesting that the method has high level of accuracy. The HPLC chromatograms in Fig. 2 showed adequate separation and the UV spectra showed good detection of DCQA and CA. Specificity of our method was evaluated by comparing the chromatograms of the standard versus the sample solution. From their 


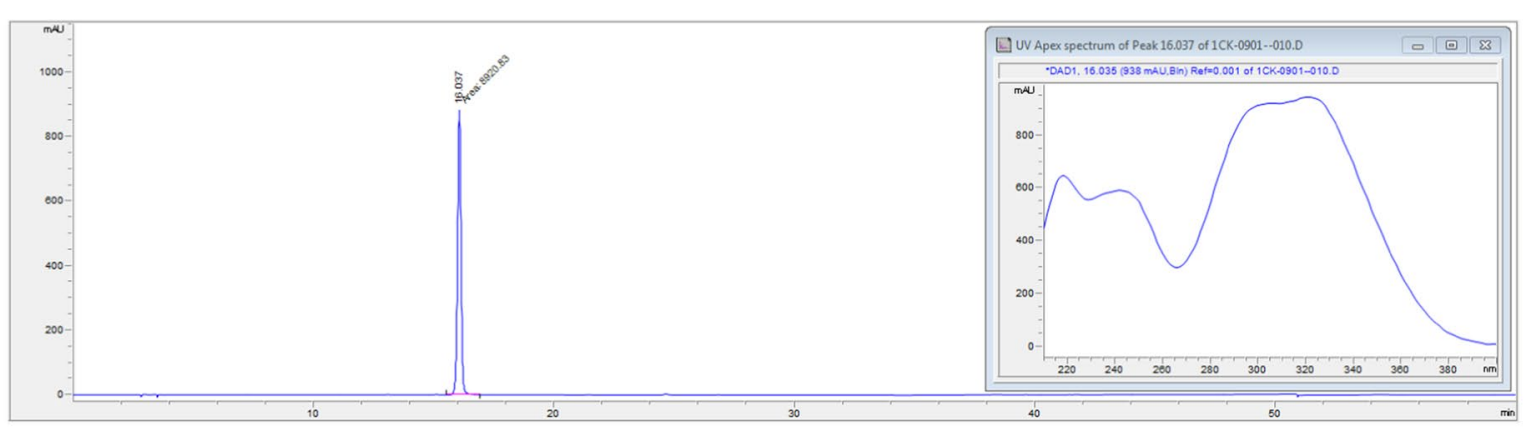

(A)

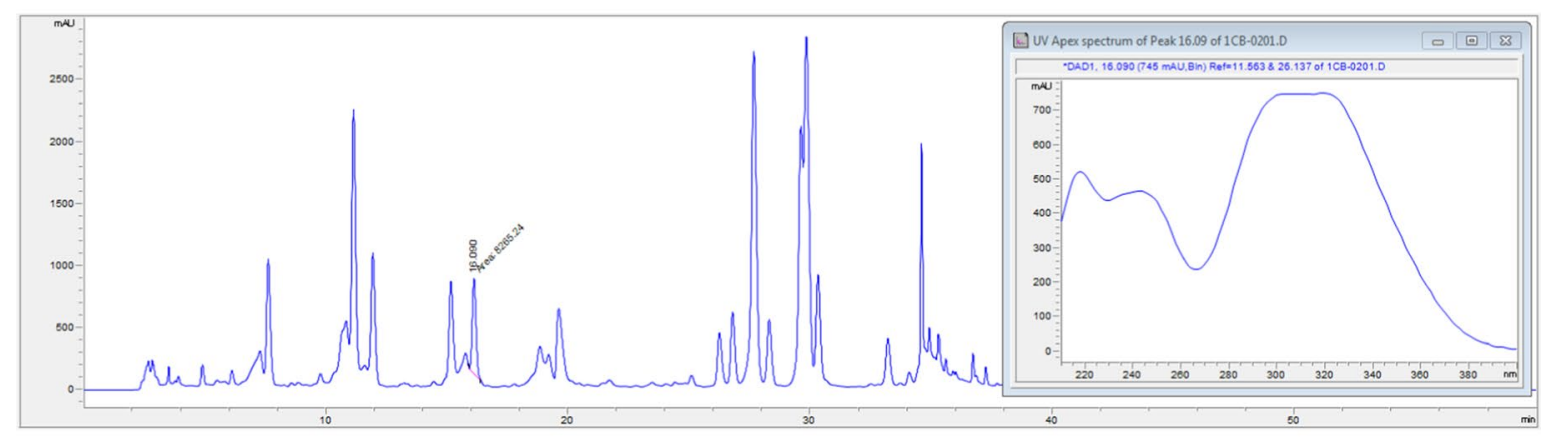

(B)

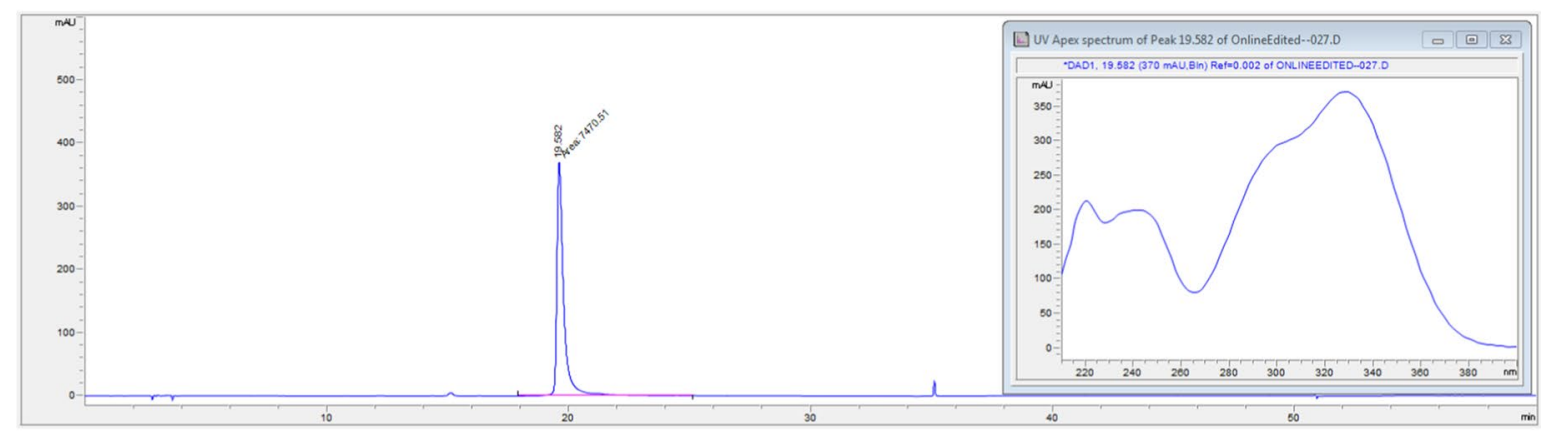

(C)

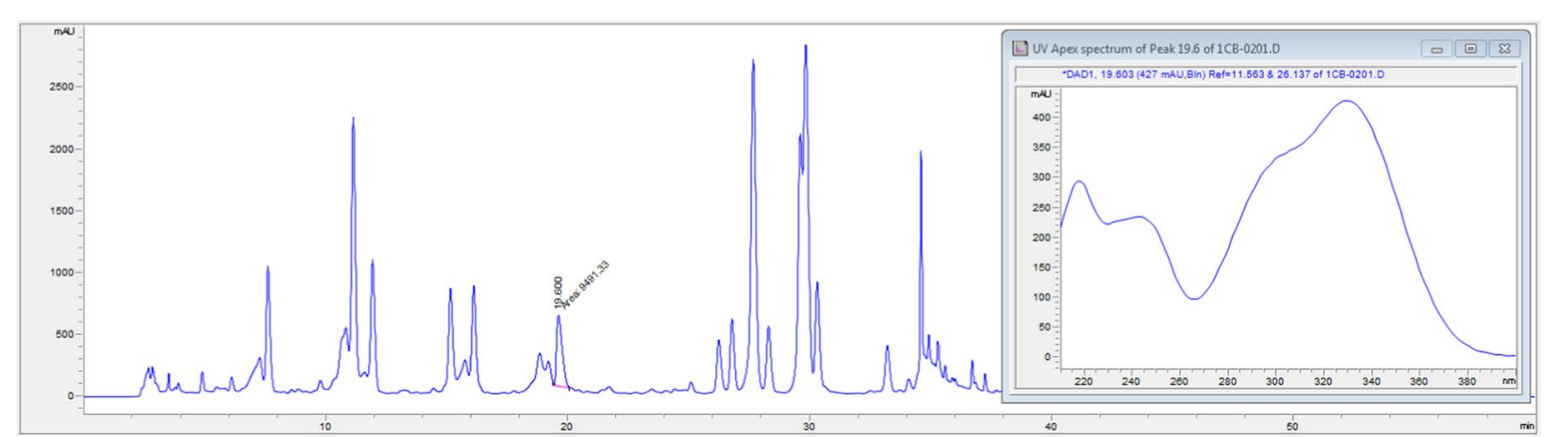

(D)

Fig. 2 HPLC chromatograms and specificity of 1,5-dicaffeoylquinic acid (A), 1,5-dicaffeoylquinic acid in MST (B), chicoric acid (C) and chicoric acid in MST (D) 
corresponding retention time and UV spectra in Fig. 2, we can see that DCQA and CA are present in MST. This indicates that our HPLC approach achieved specificity by exhibiting good resolution of chromatographic peaks associated with DCQA and CA.

Quantification parameters for DCQA and CA were examined under the HPLC conditions described above. Calibration curves for the isolated compounds were generated by mapping the peak areas obtained from HPLC analyses of solutions with various known concentrations of DCQA and CA. Linear regression was used to fit the data and generate the calibration curves, and additional statistics were used to assess the linearity. The linearity was evaluated by testing, five solutions with various concentrations of DCQA and CA over a range from $0.025-0.4$ and $0.00625-0.1 \mathrm{mg} / \mathrm{mL}$, respectively $(\mathrm{n}=3)$. The regression equation was calculated by plotting the peak area $(Y)$ versus the DCQA and CA concentrations $(X)$ expressed in $\mathrm{mg} / \mathrm{mL}$. Correlation coefficients $\left(r^{2}\right)$ of 1.0000 were obtained for both compounds indicating a strong linear relationship between peak area (Table 1) and DCQA and CA concentrations.

The LOD values obtained in our study were $5.46 \times 10^{-3}$ for DCQA and $0.37 \times 10^{-3} \mathrm{mg} / \mathrm{mL}$ for CA, whereas the LOQ values were $16.54 \times 10^{-3}$ for DCQA and $1.14 \times 10^{-3} \mathrm{mg} / \mathrm{mL}$ for CA. These values establish that the analytical method developed in this study has a high sensitivity for quantifying DCQA and CA derived from MST (Table 1).
Previous studies on the development of analytical method for quantifying DCQA and CA $[29,30]$ reported the $r^{2}$ values of DCQA and CA to be 0.9989 and 0.9997 , respectively. LOD values were $11.21 \times 10^{-3} \mathrm{mg} / \mathrm{mL}$ for DCQA, and $0.65 \times 10^{-3} \mathrm{mg} / \mathrm{mL}$ for CA, and LOQ values were $13.12 \times 10^{-3} \mathrm{mg} / \mathrm{mL}$ for DCQA, $2.17 \times 10^{-3} \mathrm{mg} / \mathrm{mL}$ for CA. Comparing our results, the LOD and LOQ values for our method were much lower suggesting that our method can produce more accurate and reliable detection and quantification of DCQA and CA even in small amounts.

The accuracy of the analytical method was measured by spiking MST $(50 \mathrm{mg} / \mathrm{mL})$ with known concentrations of DCQA and CA standard solutions $(0.125-1.0 \mathrm{mg})$. The recovery of each substance was established by comparing the detected amount and the original spiked amount of the compound. These accuracy tests were conducted in quadruplicate by using four injections, and analyses were carried out at least four times. Table 2 shows that the percent recovery ranges from 101.16-104.18\% for DCQA and $97.55-108.49 \%$ for CA. All values obtained were within the acceptable range suggesting that the analytical method is highly accurate.

Precision was established by measuring the intra- and inter-day precision of the HPLC method, the results of which are shown in Tables 3 and 4. The coefficient of variance of the precision values for DCQA ranged from 0.29 to $1.00 \%$ for intra-day precision experiments and 0.42 to $0.62 \%$ for inter-day precision experiments. The variance in precision values for CA ranged from 0.15 to $1.21 \%$

Table 1 Linearity, LOD, and LOQ of 1,5-dicaffeoylquinic acid (DCQA) and chicoric acid (CA)

\begin{tabular}{lllllll}
\hline Compound & $\mathbf{t}_{\boldsymbol{R}}$ & Range $(\mathbf{m g} / \mathbf{m L})$ & Calibration equation $^{\mathbf{a}}$ & $\mathbf{r}^{\mathbf{2} \mathbf{b}}$ & LOD $(\mathbf{m g} / \mathbf{m L})$ & $\mathbf{L O Q}(\mathbf{m g} / \mathbf{m L})$ \\
\hline DCQA & 16.0 & $0.025-0.4$ & $Y=31569 X+41.782$ & 1.0000 & $5.46 \times 10^{-3}$ & $16.54 \times 10^{-3}$ \\
CA & 19.6 & $0.00625-0.1$ & $Y=74846 X+21.402$ & 1.0000 & $0.37 \times 10^{-3}$ & $1.14 \times 10^{-3}$ \\
\hline
\end{tabular}

${ }^{\mathrm{a}} \mathrm{Y}=$ peak area, $\mathrm{X}=$ concentration of standards $(\mathrm{mg} / \mathrm{mL})$

$\mathrm{b} r^{2}=$ correlation coefficient for five calibration data points $(n=3)$

Table 2 Accuracy for the determination of 1,5-dicaffeoylquinic acid (DCQA) and chicoric acid (CA) contents

\begin{tabular}{|c|c|c|c|c|c|c|c|}
\hline \multirow[t]{2}{*}{ Compound } & \multirow{2}{*}{$\begin{array}{l}\text { Spiked amount } \\
\text { (mg) }\end{array}$} & \multicolumn{4}{|c|}{ Recovery (\%) } & \multirow[t]{2}{*}{ Average (\%) } & \multirow[t]{2}{*}{ RSD (\%) } \\
\hline & & $1 \mathrm{st}$ & $2 n d$ & $3 r d$ & 4th & & \\
\hline \multirow[t]{4}{*}{ DCQA } & 0.125 & 103.96 & 103.49 & 103.79 & 103.33 & 103.64 & 0.27 \\
\hline & 0.25 & 103.83 & 103.04 & 103.51 & 103.66 & 103.51 & 0.33 \\
\hline & 0.5 & 101.16 & 101.90 & 101.61 & 101.73 & 101.60 & 0.31 \\
\hline & 1.0 & 103.96 & 103.52 & 103.90 & 104.18 & 103.89 & 0.27 \\
\hline \multirow[t]{4}{*}{ CA } & 0.125 & 108.49 & 107.61 & 106.67 & 108.02 & 107.70 & 0.72 \\
\hline & 0.25 & 106.51 & 104.16 & 106.48 & 107.01 & 106.04 & 1.20 \\
\hline & 0.5 & 101.46 & 99.33 & 101.63 & 101.40 & 100.96 & 1.08 \\
\hline & 1.0 & 97.60 & 99.64 & 99.66 & 97.55 & 98.61 & 1.22 \\
\hline
\end{tabular}


Table 3 Intra-day precision for the determination of 1,5-dicaffeoylquinic acid (DCQA) and chicoric acid (CA) contents

\begin{tabular}{|c|c|c|c|}
\hline \multirow[t]{2}{*}{ Compound } & \multirow{2}{*}{$\begin{array}{l}\text { MST } \\
\text { Concentration } \\
\text { (mg/mL) }\end{array}$} & \multicolumn{2}{|l|}{ Intra-day $(n=3)$} \\
\hline & & $\begin{array}{l}\text { Measured } \\
\text { content }(\mathrm{mg} / \mathrm{g})\end{array}$ & RSD (\%) \\
\hline \multirow[t]{3}{*}{ DCQA } & 50 & 1.238 & 1.00 \\
\hline & 60 & 1.236 & 0.42 \\
\hline & 70 & 1.233 & 0.29 \\
\hline \multirow[t]{3}{*}{ CA } & 50 & 0.389 & 1.21 \\
\hline & 60 & 0.389 & 0.15 \\
\hline & 70 & 0.383 & 1.09 \\
\hline
\end{tabular}

Table 4 Inter-day precision for the determination of 1,5-dicaffeoylquinic acid (DCQA) and chicoric acid (CA) contents

\begin{tabular}{|c|c|c|c|}
\hline \multirow[t]{2}{*}{ Compound } & \multirow{2}{*}{$\begin{array}{l}\text { MST } \\
\text { Concentration } \\
(\mathrm{mg} / \mathrm{mL})\end{array}$} & \multicolumn{2}{|l|}{ Inter-day $(n=5)$} \\
\hline & & $\begin{array}{l}\text { Measured } \\
\text { content }(\mathrm{mg} / \mathrm{g})\end{array}$ & RSD (\%) \\
\hline \multirow[t]{3}{*}{ DCQA } & 50 & 1.229 & 0.43 \\
\hline & & 1.213 & 0.42 \\
\hline & & 1.242 & 0.62 \\
\hline \multirow[t]{3}{*}{ CA } & 50 & 0.380 & 0.42 \\
\hline & & 0.384 & 0.60 \\
\hline & & 0.389 & 0.11 \\
\hline
\end{tabular}

for intra-day precision experiments and 0.11 to $0.60 \%$ for inter-day precision experiments, respectively. These values are lower than $2 \%$ which meets the criteria recommended by the ICH guidelines. The results indicate excellent reliability of the analytical method for quantifying DCQA and CA derived from MST. Furthermore, when comparing the intra- and inter-day RSD mean values, a minor difference was observed between the two, but the latter values were significantly higher. It indicates that these compounds are relatively stable after being dissolved over time.

Several studies have investigated caffeic acid ester derivatives, such as DCQA and CA. These compounds are a type of hydroxycinnamic acid that has various bioactivities that include anti-oxidant [31], anti-inflammatory [32], anti-HIV [33], anti-nociceptive [34], and neuroprotective behaviors [35]. Moreover, our previous works were mainly focused on validating various marker compounds present in medicinal plant extracts [36-38].

In this study, we validated the HPLC analytical method for quantifying DCQA and CA as marker compounds for MST. To the best of our knowledge, this is the first study to establish an analytical method that utilizes HPLC-DAD to quantify these compounds in MST. The objective of our validation study was to establish a method for quantifying the compounds of interest. As described in the results section, our HPLCDAD method proved to be an efficient and effective analytical technique that had satisfactory accuracy and precision to be used as a routine analytical method.

The consumption of bioactive compounds from plantderived foods is a promising strategy for strengthening immunity and preventing illness. Hydroxycinnamic acids, such as DCQA and CA, have many health benefits as mentioned above. These bioactivities suggest that these compounds have great potential for treating an array of problems in the human body. This motivates additional studies into DCQA and CA as functional food ingredients, especially because our collective understanding of these compounds is still in its infancy. In this study, the analytical method was validated for quantifying DCQA and CA from MST. They were quantified from MST using a novel HPLC-DAD method. The validation parameters employed in our analytical methodology provide excellent results in terms of specificity, precision, and accuracy. The findings of our analysis support the use of the developed method for accurately identifying and quantifying DCQA and CA from MST in routine analyses and large-scale extraction processes. Moreover, our established optimized method can provide the first steps in developing health-related functional products and pharmaceuticals derived from MST.

\section{Acknowledgements}

Not applicable.

\section{Authors' contributions}

HDL, HPLC analysis and method validation; LAP, data analysis and writing; SL, data curation of reference compounds; KSK, experimental design and data curation; $\mathrm{KH}$, data processing and data analysis; $\mathrm{HK}$, research funding and experimental design; SL, experimental design and writing. All authors read and approved the final manuscript.

\section{Funding}

This study was supported by grants from UNDBIO Co. Ltd., Republic of Korea.

Availability of data and materials

Not applicable.

\section{Declarations}

Competing interests

There is no conflict of interests.

\section{Author details}

${ }^{1}$ Department of Plant Science and Technology, Chung-Ang University, Anseong 17546, Republic of Korea. ${ }^{2}$ Department of Life Science, Gachon University, Seongnam 13120, Republic of Korea. ${ }^{3}$ College of Korean Medicine, Gachon University, Seongnam 13120, Republic of Korea. ${ }^{4}$ UNDBIO Co. Ltd. Uijeongbu 11622, Republic of Korea. ${ }^{5}$ Natural Product Institute of Science and Technology, Anseong 17546, Republic of Korea. 
Received: 14 May 2021 Accepted: 24 June 2021

Published online: 01 July 2021

\section{References}

1. Bae KH (1999) The medicinal plants of Korea. Kyo-Hak Publishing Co., Seoul, pp 655-656

2. Mingarro DM, Plaza A, Galán A, Vicente JA, Martínez MP, Acero N (2015) The effect of five Taraxacum species on in vitro and in vivo antioxidant and antiproliferative activity. Food Funct 6:2787-2793

3. Kenny O, Brunton NP, Walsh D, Hewage CM, McLoughlin P, Smyth TJ (2015) Characterisation of antimicrobial extracts from dandelion root (Taraxacum officinale) using LC-SPE-NMR. Phytother Res 29:526-532

4. Ma C, Zhu L, Wang J, He H, Chang X, Gao J, Shumin W, Yan T (2015) Antiinflammatory effects of water extract of Taraxacum mongolicum hand.Mazz on lipopolysaccharide-induced inflammation in acute lung injury by suppressing PI3K/Akt/mTOR signaling pathway. J Ethnopharmacol 168:349-355

5. Yoon C, Ko W, Lee D, Kim D, Kim J, Choi M, Kim Y (2017) Taraxacum coreanum protects against glutamate-induced neurotoxicity through heme oxygenase- 1 expression in mouse hippocampal HT22 cells. Mol Med Rep 15:2347-2352

6. Yamabe N, Kang KS, Lee AY, Lee D, Choi JM, Lee S, Park JY, Hwang GS, Kim HY, Cho EJ, Lee S (2014) Identification of anti-cancer active components of Taraxacum coreanum on human gastric cancer AGS cells. J Appl Biol Chem 57:187-190

7. Yang HJ, Park KW, Kim HS, Cho SM, Park KM (2010) Effect of anti-atopic allergic reaction in response to oriental herb extracts. Korean J Food Sci Technol 42:109-114

8. Lee AY, Choi JM, Lee S, Kim HY, Lee S, Cho EJ (2013) The protective effects of the ethyl acetate fraction and flavonoids from Taraxacum coreanum against oxidative stress in neuronal cells induced by hydrogen peroxide and amyloid beta. Korean J Pharmacogn 44:263-268

9. Lee S, Han S, Kim HM, Lee JM, Mok SY, Lee S (2011) Isolation and identification of phytochemical constituents from Taraxacum coreanum. J Korean Soc Appl Biol Chem 54:73-78

10. Mo EJ, Ahn JH, Jo YH, Kim SB, Hwang BY, Lee MK (2017) Inositol derivatives and phenolic compounds from the roots of Taraxacum coreanum. Molecules 22:1349

11. Lipschitz S (1979) Genus Saussurea DC. (Asteraceae). Nauka, Leningrad, pp 1-281 (In Russian and Latin)

12. Oh BU, Jo DG, Kim KS, Jang CG (2005) Endemic vascular plants in the Korean peninsula. Korea National Arboretum, Pocheon, pp 1-205

13. Tu Y, Sun L, Guo M, Chen W (2013) The medicinal uses of Callicarpa L. in traditional Chinese medicine: an ethnopharmacological, phytochemical and pharmacological review. J Ethnopharmacol 146:465-481

14. Wang HB, Zuo JP, Qin GW (2010) One new sesquiterpene from Saussurea laniceps. Fitoterapia 81:937-939

15. Li LB, Cao KX, Tian PW, Xiao GD, Huang RS (2019) Sesquiterpenoids from Saussurea laniceps and their chemotaxonomic significance. Biochem Syst Ecol 84:37-41

16. Fan CQ, Zhu XZ, Zhan ZJ, Ji XQ, Li H, Yue JM (2006) Lignans from Saussurea conica and their NO production suppressing activity. Planta Med 72:590-595

17. Dai J, Zhao C, Wang Y, Zhang Q, Liu ZL, Zheng R, Yang L (2001) Two new sesquiterpenes from the Chinese herb Saussurea petrovii and their antibacterial and antitumor activity. J Chem Res 2001:74-75

18. Li XH, Qi HY, Shi YP (2008) Dammarane-and taraxastane-type triterpenoids from Saussurea oligantha Franch. J Asian Nat Prod Res 10:397-402

19. Rao KS, Babu GV, Ramnareddy YV (2007) Acylated flavone glycosides from the roots of Saussurea lappa and their antifungal activity. Molecules $12: 328-344$
20. Singh IP, Talwar KK, Arora JK, Chhabra BR, Kalsi PS (1992) A biologically active guaianolide from Saussurea lappa. Phytochemistry 31:2529-2531

21. Talwar KK, Singh IP, Kalsi PS (1992) A sesquiterpenoid with plant growth regulatory activity from Saussurea lappa. Phytochemistry 31:336-338

22. Ohn J, Kim JH (2012) Intake pattern and needs assessment for the development of web-contents on health functional foods according to age of adults. Korean J Commun Nutr 17:26-37

23. Nugroho A, Kim KH, Lee KR, Alam MB, Choi JS, Kim WB, Park HJ (2009) Qualitative and quantitative determination of the caffeoylquinic acids on the Korean mountainous vegetables used for chwinamul and their peroxynitrite-scavenging effect. Arch Pharm Res 32:1361-1367

24. Nugroho A, Kim MH, Lee JH, Kim JD, Lee KR, Choi JS, Yoo YM, Park HJ (2011) Polyphenol analysis and peroxynitrite scavenging effect of the extracts from eight Korean mountainous vegetable. Korean J Pharmacogn 42:38-45

25. Xue Y, Zhang S, Du M, Zhu MJ (2017) Dandelion extract suppresses reactive oxidative species and inflammasome in intestinal epithelial cells. J Funct Foods 29:10-18

26. Green JM (1996) Peer reviewed: a practical guide to analytical method validation. Anal Chem 68:305A-309A

27. Shabir GA (2003) Validation of high-performance liquid chromatography methods for pharmaceutical analysis: understanding the differences and similarities between validation requirements of the US Food and Drug Administration, the US Pharmacopeia and the International Conference on Harmonization. J Chromatogr A 987:57-66

28. Guideline IHT (2005) Validation of analytical procedures: text and methodology. Q2 R1 1(20):05

29. Yilmaz MA, Cakir O, Arica E, Yener I, Otludil B, Alma MH, Ertas A (2018) An LC-MS/MS method validation for the phytochemical quantification of four edible plants. J Inst Sci Technol 8:179-187

30. Nugroho A, Lim SC, Karki S, Choi JS, Park HJ (2015) Quantitative determination of five phenolic peroxynitrite-scavengers in nine korean native compositae herbs. Nat Prod Sci 21:155-161

31. Shahidi F, Chandrasekara A (2009) Hydroxycinnamates and their in vitro and in vivo antioxidant activities. Phytochem Rev 9:147-170

32. Cunha FM, Duma D, Assreuy J, Buzzi FC, Niero R, Campos MM, Calixto JB (2004) Caffeic acid derivatives: in vitro and in vivo anti-inflammatory properties. Free Radic Res 38:1241-2125

33. Bailly F, Cotelle P (2005) Anti-HIV activities of natural antioxidant caffeic acid derivatives: toward an antiviral supplementation diet. Curr Med Chem 12:1811-1818

34. de Campos BF, Franzoi CL, Antonini G, Fracasso M, Filho VC, Yunes RA (2009) Antinociceptive properties of caffeic acid derivatives in mice. Eur J Med Chem 44:4596-4602

35. Fu W, Wang H, Ren X, Yu H, Lei Y, Chen Q (2017) Neuroprotective effect of three caffeic acid derivatives via ameliorate oxidative stress and enhance PKA/CREB signaling pathway. Behav Brain Res 328:81-86

36. Lee JS, Paje LA, Choi WH, Cho EJ, Kim HY, Jacinto SD, Lee S (2020) Validation of an optimized HPLC/UV method for the quantification of flavonoids in lotus. Appl Biol Chem 63:1-6

37. Lee JS, Paje LA, Rodriguez JP, Kang KS, Hahm DH, Shim JS, Choi YJ, Lee $\mathrm{S}$ (2020) Validation of an HPLC/UV analysis method for cirsimaritin in Cirsium japonicum var. maackii. Korean J Pharmacogn 51:217-221

38. Lee JS, Quilantang NG, Hahm DH, Kang KS, Jacinto SD, Choi YJ, Lee SC, Lee S (2020) Optimization of extraction conditions of continentalic and kaurenoic acids from Aralia continentalis by HPLC/UV and their validation. J Chromatogr Sci 58:672-677

\section{Publisher's Note}

Springer Nature remains neutral with regard to jurisdictional claims in published maps and institutional affiliations. 